Sharif University of Technology
Scientia Iranica
SCIENTIA
IRAN I CA

\title{
Effect of wind tunnel wall porosity on the flow around an oscillating airfoil at transonic speeds
}

\author{
A. Golestani ${ }^{a, *}$, M.R. Soltani ${ }^{\mathrm{b}}$ and M. Masdari ${ }^{\mathrm{c}}$ \\ a. Department of Mechanical Engineering, University of Tabriz, Tabriz, Iran. \\ b. Department of Aerospace Engineering, Sharif University of Technology, Tehran, Iran. \\ c. Department of New Science and Technology, University of Tehran, Tehran, Iran.
}

Received 3 July 2015; received in revised form 6 April 2016; accepted 10 May 2016

\section{KEYWORDS}

Supercritical;

Oscillating;

Porosity;

Transonic;

Experimental.

\begin{abstract}
The effect of porosity in oscillating situations (to the authors' knowledge, for the first time) on a supercritical airfoil (SC0410) has been experimentally investigated. Tests have been carried out in an open circuit suction-type wind tunnel at a free stream Mach number of $M=0.80$. Both static and dynamic (pitching) tests have been carried out on the mentioned airfoil. The oscillation frequency for the unsteady tests has been set to 3 and $6 \mathrm{~Hz}$. The amplitude of frequency is $\pm 1 \mathrm{deg}$. The effect of porosity has been surveyed on the magnitude of pressure fluctuations, phase shift, and lift coefficient loop. The investigations show that increasing porosity in the test section of transonic regime, contrary to the impression, does not necessarily improve results.
\end{abstract}

(C) 2017 Sharif University of Technology. All rights reserved.

\section{Introduction}

Shock interaction between the model and the wind tunnel walls is an important phenomenon that may cause choking in the test section. This difficulty was one of the main obstacles to test programs for Mach numbers ranging from 0.8 up to 1.2 . To overcome this problem, slotted walls were proposed and implemented first in NACA LANGLEY wind tunnel [1].

However, additional studies showed that slotted walls do not give satisfactory results when the flow is subsonic. Hence, the perforated ones were introduced in the mid-1950s [2]. Further investigations during 60s and $70 \mathrm{~s}$ showed that perforated walls provide better results for the subsonic and even for the transonic flow regimes [3]. To improve flow quality, the perforations are arranged in an inclined position. By inclined holes, the choked flow from the test section is sucked into

\footnotetext{
*. Corresponding author.

E-mail addresses: Ali_goles@tabrizu.ac.ir (A. Golestani); msoltani@sharif.edu (M.R. Soltani); m.masdari@ut.ac.ir (M. Masdari)
}

the plenum chamber, eliminating choking problem and the shock wave interactions between the model and the walls as well [4].

It should be mentioned that for a test section with perforated walls, the boundary layer growth is faster than that of the solid ones with the same flow conditions; thus, the blockage for these types of walls increases and the flow accelerates in the test section which in turn will affect the flow uniformity in that region. To overcome the aforementioned problems, suction must be implemented for the walls through the plenum chamber [5]. The suction controls the boundary layer thickness and eliminates the blockage and choking problems [6].

Over the past few years, many experimental [7-9] and numerical [10-12] studies have been devoted to wall interferences of wind tunnel at transonic regime and their consequences. In addition, many research papers have been published about the effect of porosity based on optimization $[13,14]$. However, almost all of these investigations are related to the effect of porosity on the static tests. For example, Rasuo [15] mentioned that by increasing the porosity, the lift coefficient for 
Table 1. History of dynamic tests on supercritical airfoils in transonic regime based on thickness.

\begin{tabular}{clc}
\hline Thickness & \multicolumn{1}{c}{ Airfoils name } & Reference \\
\hline $16.5 \%$ & NLR 7301 & {$[19]$} \\
$14 \%$ & SC(2)-0714 & {$[20]$} \\
$14 \%$ & DRA 2303 & {$[21]$} \\
$14 \%$ & SC(2)-0414 & {$[22]$} \\
$11 \%$ & BAC 3-11/RES/30/21 & {$[23]$} \\
$10 \%$ & Present airfoil & \\
\hline
\end{tabular}

the airfoil decreases. Werling [16] pointed out that by decreasing the porosity, the Mach number in the test section increases. Nevertheless, to the authors' knowledge, there is no information, either experimental or theoretical, that deals with the effect of porosity on dynamic tests. The present experimental work investigates the effect of porosity on an oscillating supercritical airfoil in a transonic regime.

The airfoil under investigation is a supercritical airfoil, $\mathrm{SC}(2) 0410$, where $\mathrm{SC}(2)$ indicates supercritical (phase 2); next two digits show the airfoil design lift coefficient in tenths (0.4); the last two digits specify the airfoil maximum thickness in percent chord (10\%). The development history of supercritical airfoils was fully described by Harris [17].

Blackwell [18] studied the effect of porosity on the supercritical airfoil in a static condition. The history of dynamic tests on supercritical airfoils in transonic regime based on their thickness ratio is presented in Table 1.

Previous studies have shown that an important parameter, which has significant effects on the buffet, flutter, flow separation, etc., is the airfoil thickness [24,25]. Based on the available information from various sources shown in Table 1 , the present airfoil is the thinnest supercritical airfoil that has been tested in forced oscillating conditions up to now. (There are some investigations about thinner supercritical airfoils that belong to blade helicopter airfoils [26].)

In all of these tests, the effect of porosity on various dynamic parameters, such as magnitude of fluctuations, phase lag, shock location, aerodynamic coefficients, reduced frequency, and etc., has not been studied. In the present paper, the authors will try to answer these questions.

\section{Experimental facilities and instrumentation}

\subsection{Wind tunnel}

All tests were conducted in a trisonic wind tunnel which is functional within Mach number range of 0.4 to 2.7 at atmospheric pressure and temperature. Maximum available Reynolds number is 9 million for unit chord. The free-stream turbulence level in the test section is

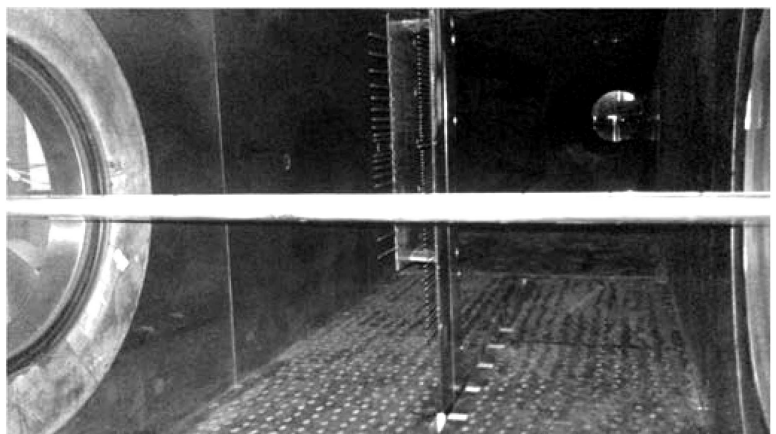

(a)

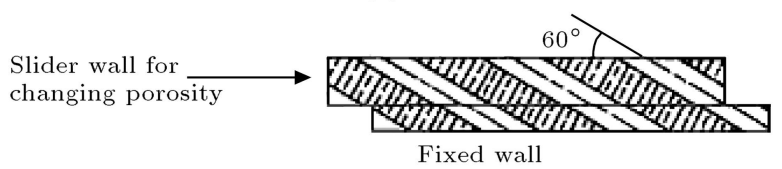

(b)

Figure 1. (a) Wind tunnel test section. (b) Sketch of slider wall for changing porosity.

less than $0.4 \%$ for all Mach numbers tested. This is an open circuit, suction-type wind tunnel and is equipped with 2 turbofan engines that operate continuously. In Figure 1, the test section of the tunnel with the model is shown. Suction from the porous walls (top and bottom) with $60^{\circ}$ diagonal holes is applied through a smaller turbofan engine. Porosity in this tunnel can vary from 0 to 6 percent. The hole diameter of perforated walls is $7 \mathrm{~mm}$ and test section dimensions are $60 \mathrm{~cm}(\mathrm{~W})$ *60 cm (H) * $150 \mathrm{~cm} \mathrm{(L).}$

As mentioned previously, to the authors' knowledge, there are no experimental data for the present airfoil (based on Table 1). Therefore, to ensure the accuracy of data acquisition as well as data reduction, correction, etc., a pretest on a NACA0012 was performed and the results were compared with results in other tunnels [27]. A sample of this comparison is shown in Figure 2 for $M_{\infty}=0.8$ and $\alpha_{0}=0^{\circ}$. The results agreed consistently with each other.

The uncertainty due to the bias and single sample precision is shown in Table 2. The maximum uncer-

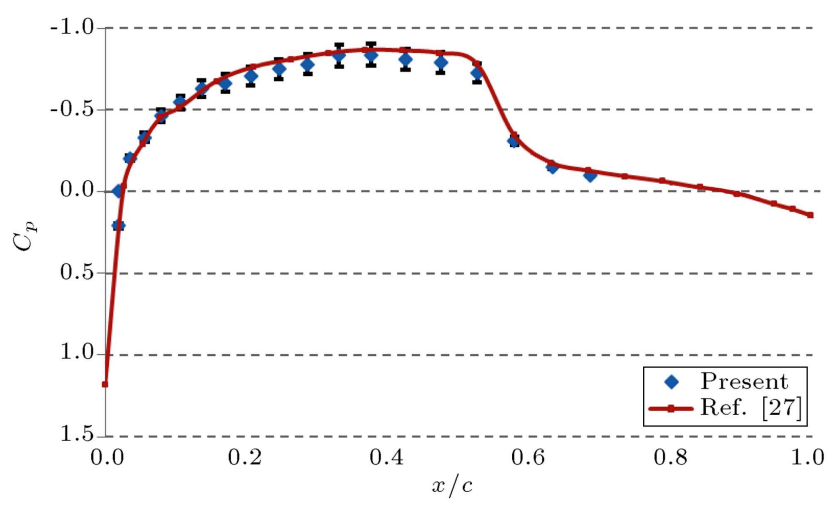

Figure 2. Pressure distribution comparison on the upper surface of NACA 0012 at $M_{\infty}=0.8$ and $\alpha_{0}=0^{\circ}$. 
Table 2. Amount of uncertainty with confidence level of $95 \%[28]$.

\begin{tabular}{ccl}
\hline & Uncertainty & \multicolumn{1}{c}{ Name of sensor } \\
\hline $\boldsymbol{c}_{\boldsymbol{p}}$ & $3.15 \%$ & Kulite \& Honeywell \\
$\boldsymbol{M}$ & $0.68 \%$ & Honeywell \\
$\boldsymbol{\alpha}$ & $1.73 \%$ & Gefran linear potentiometer \\
\hline
\end{tabular}

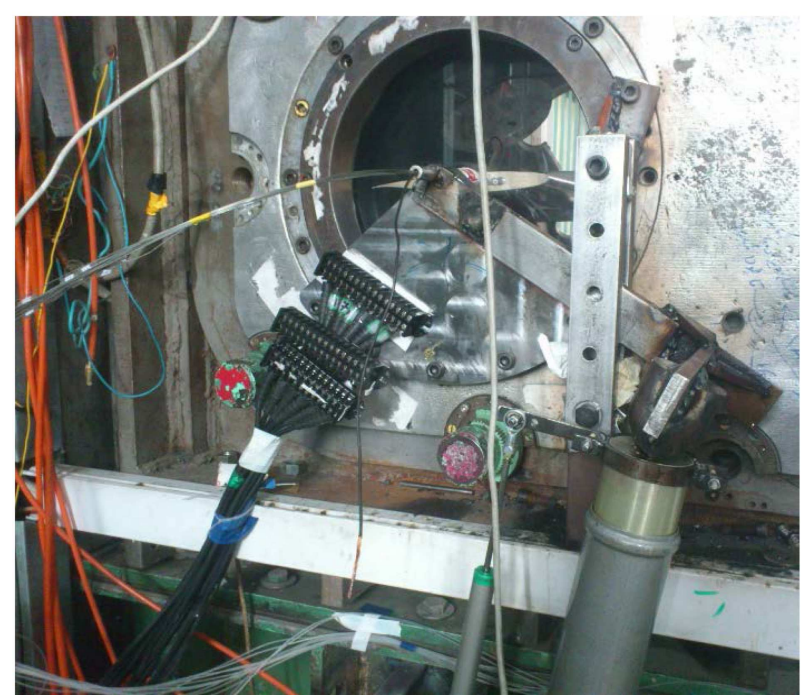

Figure 3. The model in the tunnel.

tainty calculated for the sensors, used in these tests, was less than $\pm 3.15 \%$ of the total $c_{p}$ values and is shown by the error bar in Figure 2. Based on accuracy of the system, uncertainty, and other parameters, the comparison is good enough.

\subsection{Model and oscillating mechanism}

The model has a span of $60 \mathrm{~cm}$ and a chord of $20 \mathrm{~cm}$. Figure 3 shows the model with external excitation mechanism that is mounted in one side of the test section which can oscillate the model in pitch for dynamic tests. The rotational motion of an electrical motor transfers to a reciprocating motion by a hydraulic system which allows excitation frequencies of up to $9 \mathrm{~Hz}$ and oscillation amplitude of up to $5^{\circ}$. Another electrical motor, integrated with the system, is used to adjust the mean angle of attack between -3 to $10^{\circ}$ with precision of \pm 1 minute. The pitching motion is measured by two linear potentiometers on each side of the test section. The design of the excitation system and its assembly has been conducted in such a way that allows using a shadowgraph visualization system for all dynamic test cases. The test conditions are presented in Table 3.

\subsection{Measuring instrument}

A total of 42 pressure orifices have been considered on the surfaces of the model which their locations are indicated in Table 4 for the upper and lower surfaces, respectively. These ports have been connected to the
Table 3. Test conditions.

\begin{tabular}{lc}
\hline Mach & 0.8 \\
Porosity & $2 \%$ and $6 \%$ \\
Angle of attack & $1^{\circ}$ and $2^{\circ}$ \\
Oscillation frequency & $3-6 \mathrm{~Hz}$ \\
Reduced frequency & 0.0074 and 0.0148 \\
Oscillation amplitude & $\pm 1^{\circ}$ \\
Transition & Free \\
Reynolds number & $2.2 \mathrm{e} 6$ \\
\hline
\end{tabular}

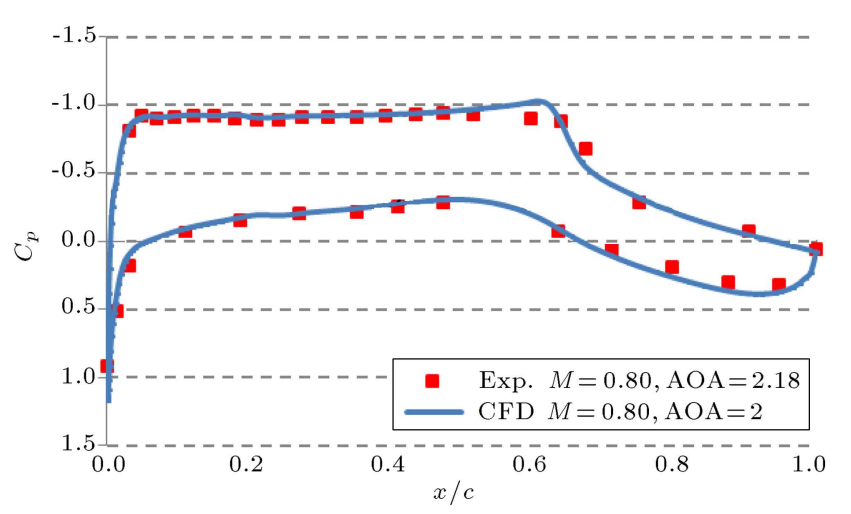

Figure 4. Pressure distribution comparison between experimental results and CFD on present airfoil at $M=0.8$ and $\alpha_{0}=2^{\circ}$.

high-sensitive pressure transducers (Kulite-CCQ-093 Series) inside the model by using short steel tubes to ensure real-time measurement of the pressure signals during dynamic tests (the time lag has been $0.09 \mathrm{sec}$ ). The data of sensors are low-pass filtered (cut off frequency: $200 \mathrm{~Hz}$ ) and sampled at $2 \mathrm{kHz}$. Time of data acquisition for each condition has been $5 \mathrm{sec}$.

A few computational runs were performed for further comparison of results. Figure 4 is a sample at $M_{\infty}=0.8$ and $\alpha_{0}=2^{\circ}$. As seen from this figure, the location of the shock in the numerical calculations has good consistency with that obtained from the experimental data. The slight differences between the pressure distribution points, especially after the shock location, are due to the free stream turbulence, model accuracy, roughness of the airfoil, etc. Note that in the CFD (Computational Fluid Dynamic) simulation, no roughness was used. The turbulence model for numerical computations has been K-Omega SST with $y^{+}<4$ (a criterion for evaluating the mesh quality) [29].

\section{Definitions}

For dynamic tests, some definitions are required. On an airfoil with pitch oscillation under conditions:

$$
\alpha=\alpha_{0}+\Delta \alpha \cos \omega t
$$


Table 4. The location of pressure ports on the airfoil.

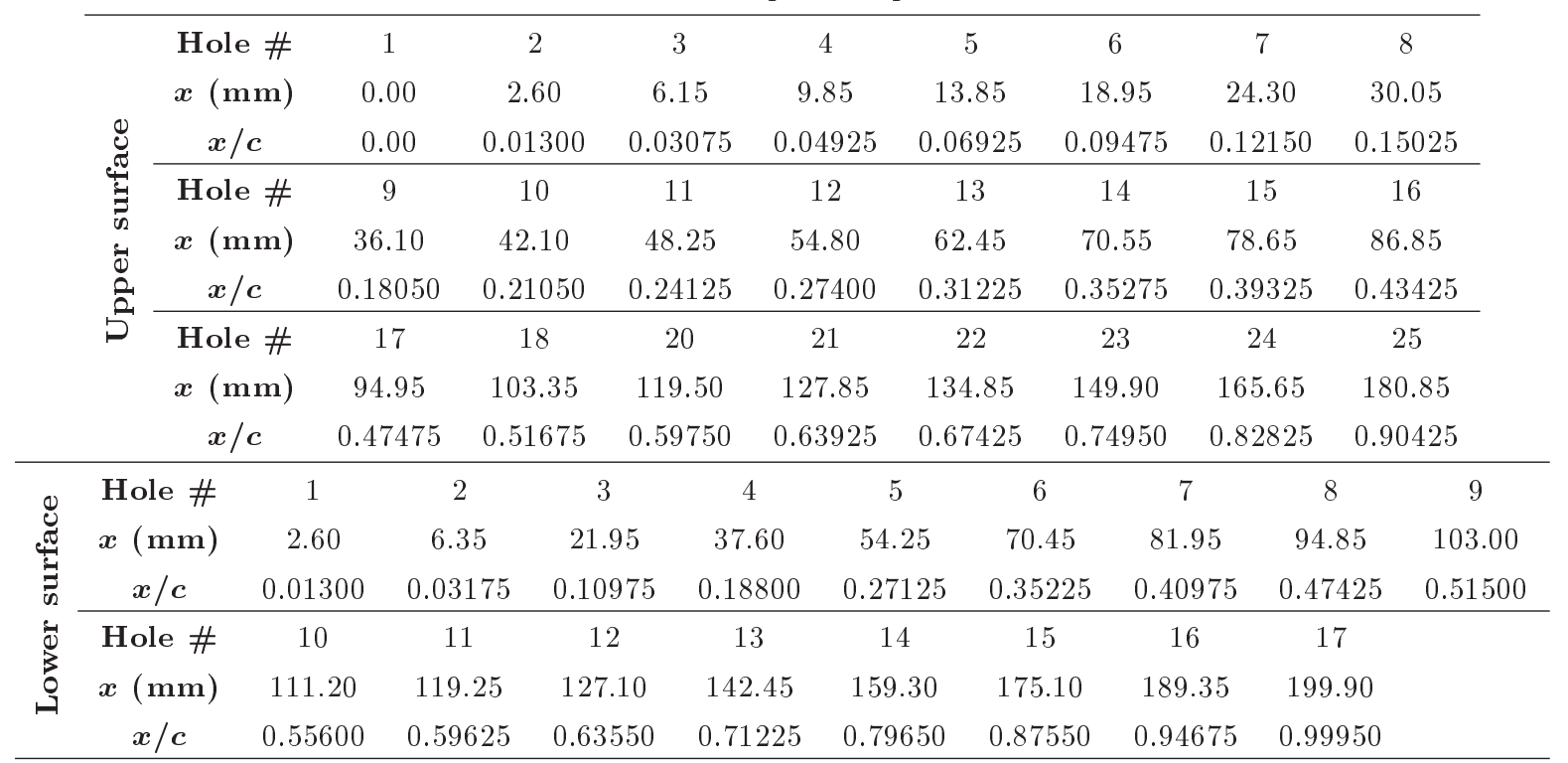
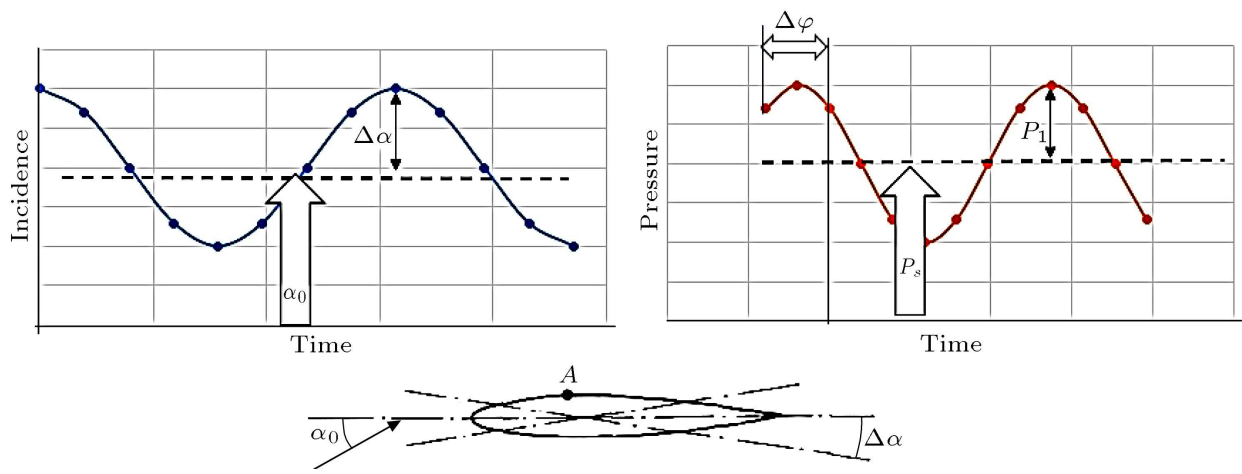

Figure 5. Descriptions of unsteady motion [19].

the measured surface pressure for a point is:

$$
P=P_{s}+\Delta P=P_{s}+P_{1} \cos (\omega t+\varphi) \text {. }
$$

When the mean angle of attack is $\alpha_{0}, \Delta \alpha$ is the amplitude of oscillation, and $\omega$ is its oscillation frequency. $P_{s}$ is the static pressure, $P_{1}$ is the magnitude of pressure fluctuations, and $\varphi$ is the phase angle that indicates the lead or lag of pressure variation for the corresponding point, i.e. point A. These definitions are further shown in Figure 5.

\section{Discussion}

Figure 6 shows that the magnitude of pressure fluctuations in an empty test section changes as porosity increases [3]. The magnitude of pressure fluctuations is almost constant for porosities from zero up to $2 \%$. There is a jump, however, for porosity from $2 \%$ to $3 \%$, and after that, the fluctuations are almost constant again. Therefore, based on the information, it was decided to study the porosity effects in dynamic test on only two situations ( $\tau=2 \%$ and $\tau=6 \%$ ).

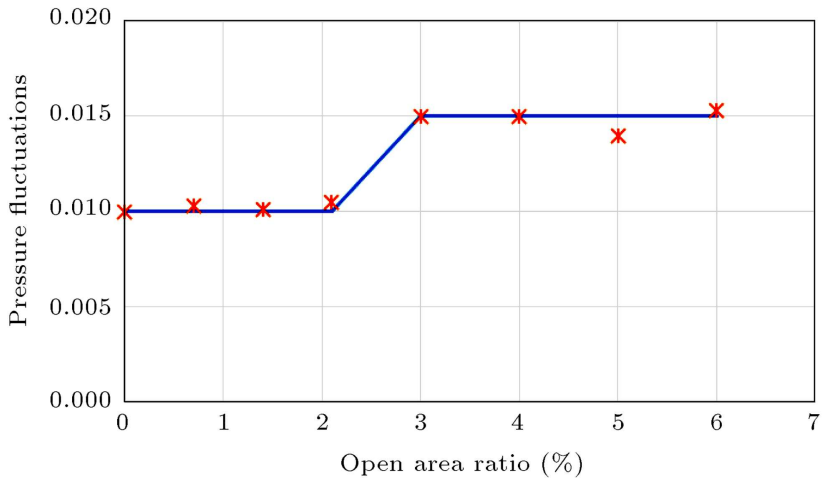

Figure 6. Magnitude of pressure fluctuations (RMS) in an empty test section wind tunnel for different porosities [3].

\subsection{First case}

Figure 7 shows magnitude of the pressure fluctuations on the upper surface of the present airfoil at $M=$ 0.80, $\alpha_{0}=0^{\circ}, \Delta \alpha= \pm 1^{\circ}$, and $f=3 \mathrm{~Hz}$ for two different wall porosities. As seen from this figure, wall porosity $(\tau)$ has significant influence on the magnitude 


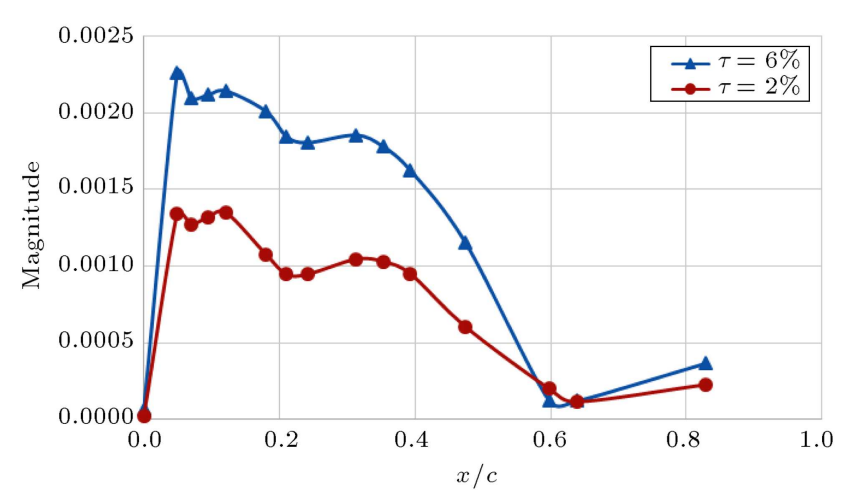

Figure 7. Effect of porosity on the magnitude of the pressure fluctuation $\left(M=0.80, \alpha_{0}=0^{\circ}, \Delta \alpha= \pm 1^{\circ}\right.$, and $f=3 \mathrm{~Hz}$.

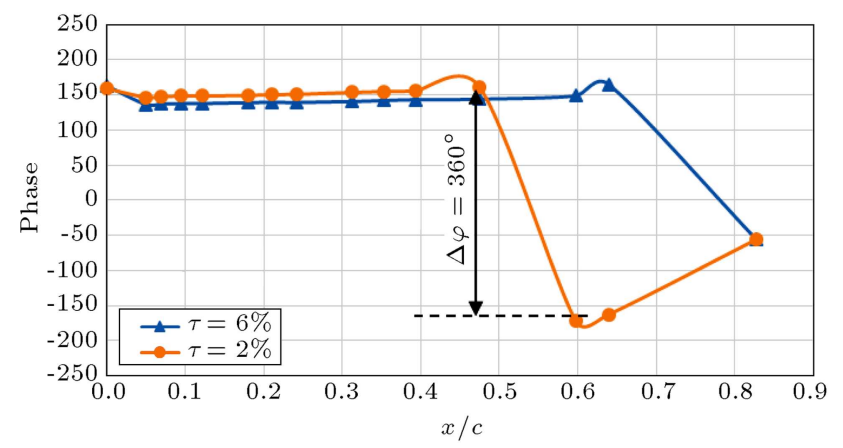

Figure 8. Effect of the porosity on the phase angle $\left(M=0.80, \alpha_{0}=0^{\circ}, \Delta \alpha= \pm 1^{\circ}\right.$, and $f=3 \mathrm{~Hz}$. $)$

of fluctuations. It has increased as the wall porosity increases from $2 \%$ to $6 \%$ like Figure 6 .

By increasing the porosity, the boundary layer on the test section walls is sucked better through applied suction by the motors. Consequently, the blockage and then the velocity decrease due to the increase of the effective area in the test section. By referring to reduced frequency formulation:

$$
k=\frac{\omega c}{2 V_{\infty}} \quad \text { (sign of flow unsteadiness), }
$$

it is obvious that decreasing velocity increases $k$ and magnitude of pressure fluctuations.

Figure 8 shows the corresponding phase angle diagram of oscillating condition for the first case. As indicated, there is a phase shift of about $360^{\circ}$ in the middle of the chord, $x / c=0.5$, for $\tau=2 \%$ due to the shock; however, for $\tau=6 \%$, the phase shift occurs near the trailing edge caused by the flow separation, not by shock.

The results for the oscillating condition are similar to those of the static condition. From Figure 9, it is obvious that for $\tau=2 \%$ in static condition, a relatively strong shock wave appears around $x / c=50 \%-60 \%$ over the model surface, while for $\tau=6 \%$, the strength of the shock wave has declined significantly.

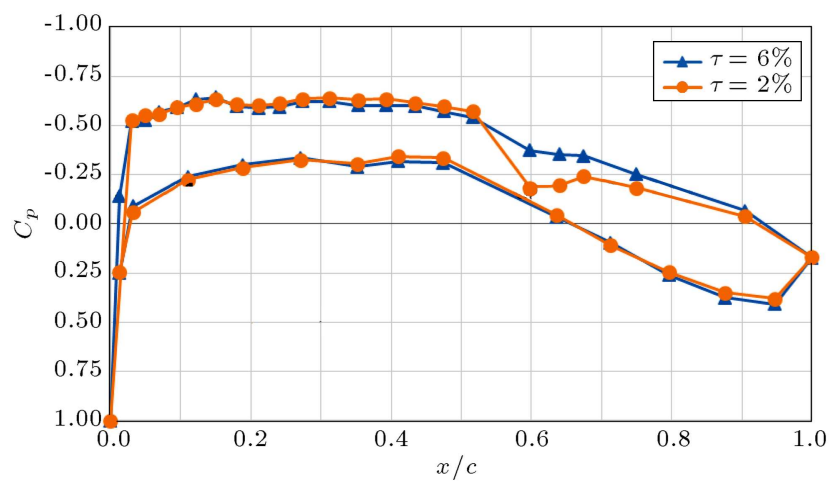

Figure 9. Effect of porosity on the static pressure distribution ( $M=0.80$ and $\alpha_{0}=0^{\circ}$.)
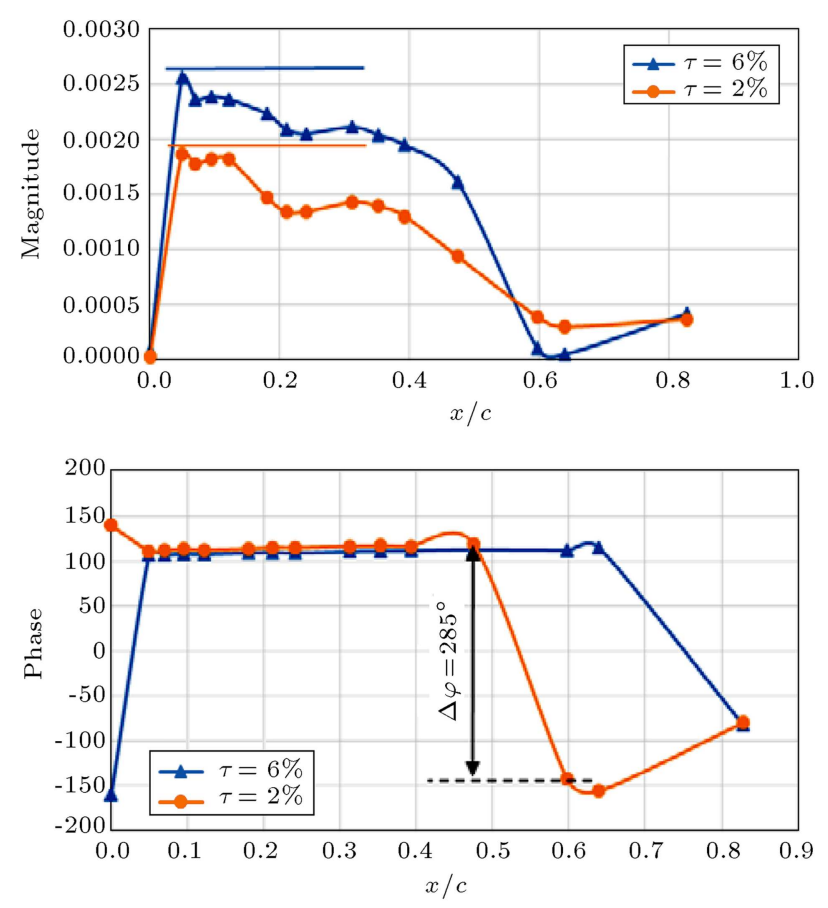

Figure 10. Magnitude and phase angle of pressure fluctuations for different porosities and $(M=0.80$, $\alpha_{0}=0^{\circ}, \Delta \alpha= \pm 1^{\circ}$, and $f=6 \mathrm{~Hz}$.)

\subsection{Second case (effect of increasing frequency)}

In Figure 10, a similar trend is depicted for higher oscillation frequency, $f=6 \mathrm{~Hz}$. Increasing frequency increases $k$; thus, the magnitude of pressure fluctuation increases in the same porosity, compared with similar values for the lower oscillation frequency $(f=$ $3 \mathrm{~Hz})$, but the corresponding phase shift $(\Delta \varphi)$ reduces. Therefore, it could be concluded that increasing the oscillation frequency will cause a decrease in $\Delta \varphi$ in the same porosity.

\subsection{Third case (effect of increasing mean angle of attack)}

The results for increasing the mean angle of attack $\left(\alpha_{0}=1^{\circ}\right)$ are shown in Figure 11. Again, by increasing 

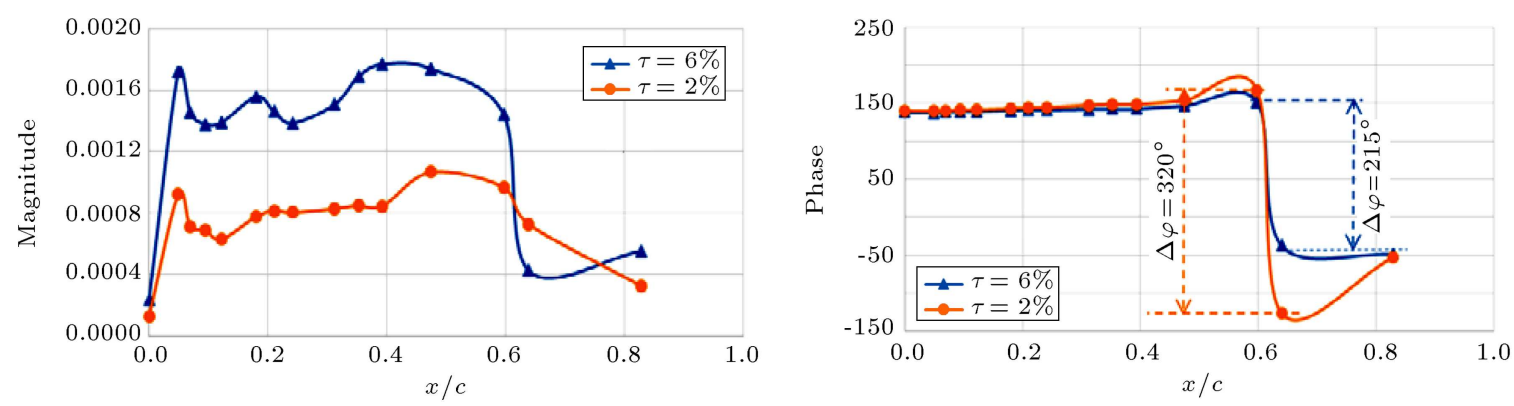

Figure 11. Magnitude and phase angle of pressure fluctuations for different porosities $\left(M=0.80, \alpha_{0}=1^{\circ}, \Delta \alpha= \pm 1^{\circ}\right.$, and $f=3$ Hz.)
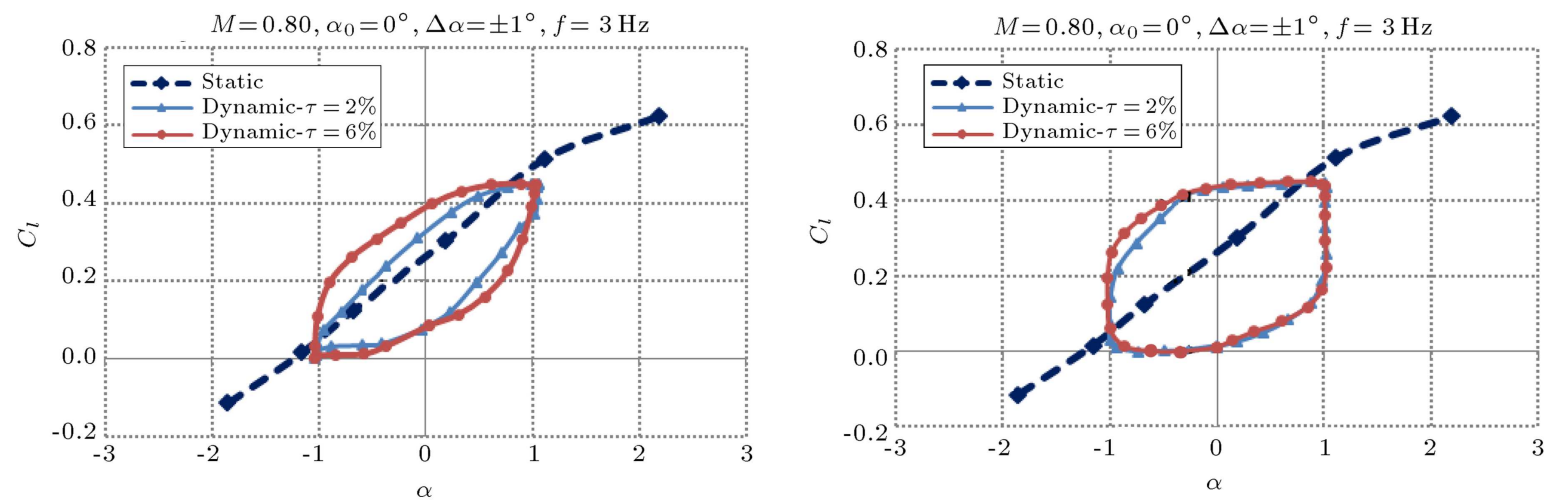

Figure 12. Effect of porosity and oscillation frequency on the lift coefficient loop $\left(M=0.80, \alpha_{0}=0^{\circ}\right.$, and $\Delta \alpha= \pm 1^{\circ}$.)

the porosity, the magnitude of fluctuations increases. Due to increasing in mean angle, the phase shift (caused by shock) has occurred in the middle of the chord for both porosities, but again, $\Delta \varphi$ for $\tau=2 \%$ is higher than corresponding changes for $\tau=6 \%$.

\subsection{Effect of porosity on lift coefficient based on reduced frequency}

Figure 12 shows the effect of wall porosity on lift coefficient obtained by integrating through $c_{p}$ from the upper and lower surfaces of the airfoil for $M=$ $0.8, \alpha_{0}=0^{\circ}$, and $\Delta \alpha= \pm 1^{\circ}$. It is obvious that $k$ has increased by increasing the frequency; thus, the lift coefficient loop would be wider (from $f=$ $3 \mathrm{~Hz}$ to $f=6 \mathrm{~Hz}$ ). However, the more important phenomenon is changing the width of the loop by changing porosity in each frequency. As mentioned, increasing the porosity decreases velocity in the test section and increases $k$ that is led to a wider loop. Also, this figure clearly shows that as the frequency increases, the influence of porosity on width of the loop diminishes.

\section{Conclusion}

A series of experiments were performed in a transonic wind tunnel on a supercritical airfoil, SC0410. To authors' knowledge, this airfoil is the thinnest supercritical airfoil that has been tested up to now.
The accuracy of the present experiments was verified by a series of tests on NACA0012, prior to testing the present supercritical airfoil. Furthermore, the uncertainty calculated in the present experimental data seems to be within the acceptable range. It should be noted that the present airfoil was tested in various conditions like static and dynamic oscillations, but in this paper, only the effects of porosity on a few dynamic conditions were presented.

Based on authors' reviews, this paper is the first fundamental study on the effect of porosity in oscillating conditions in a transonic regime.

Increasing porosity increases the effective area of the test section, so the velocity decreases. It will entail an increase in reduced frequency (sign of flow unsteadiness). And, as a result, the magnitude of pressure fluctuations increases; however, because the velocity has decreased, the phase angle caused by shock decreases. Increasing frequency of oscillations increases magnitude of pressure fluctuation (because of increasing $k$ ), but decreases phase shift.

Also, increasing the porosity increases the width of lift coefficient loop in a constant frequency (again, because of increasing $k$ ). In addition, increasing the frequency makes the lift loop wider, but diminishes the effect of porosity changes on the lift width.

However, further experiments are needed to find the effect of various parameters, such as Mach Numbers, higher reduced frequency, different porosities, 
etc., on the magnitude of pressure fluctuation, phase angle, and aerodynamic coefficients loops.

\section{Acknowledgement}

The authors would like to show their gratitude to the Mr. E. Vaziri for assistance in data preparation.

\section{Nomenclature}

$\begin{array}{ll}c & \text { Chord } \\ c_{l} & \text { Lift coefficient } \\ c_{p} & \text { Pressure coefficient } \\ f & \text { Frequency } \\ H & \text { Height } \\ k & \text { Reduced frequency } \\ L & \text { Length } \\ M & \text { Free stream Mach number } \\ P & \text { Pressure } \\ P_{1} & \text { Magnitude of pressure } \\ P_{s} & \text { Static pressure } \\ V_{\infty} & \text { Free stream velocity } \\ W & \text { Width } \\ \varphi & \text { Phase angle } \\ \Delta \varphi & \text { Phase shift due to the shock } \\ \tau & \text { Porosity ratio } \\ \alpha_{0} & \text { Mean angle of attack } \\ \Delta \alpha & \text { Amplitude of oscillation } \\ \omega & \text { Angular velocity }\end{array}$

\section{References}

1. Wright, R.N. and Ward, V.G. "NACA transonic windtunnel test sections", NACA, Virginia, Report 1231 (1955).

2. Goodmant, R. "The porous wall wind tunnel part III, reflection and absorption of shock waves at supersonic speeds", Cornell Aero. Lab., Buffalo, AD-706-A-1 (1950).

3. Mabey, D.G. "Flow unsteadiness and model vibration in wind tunnels at subsonic and transonic speeds", Royal Aircraft Establishment, Bedford, C.P. No. 1155 (I971).

4. Goethert, B.H., Physical Aspects of ThreeDimensional Wave Reflections in Transonic Wind Tunnels at Mach Number 1.2, Arnold Engineering Development Center, Tennessee, AEDC-TR-55-45 (1956).
5. Goethert, B.H., Transonic Wind Tunnel Testing, W.C. Nelson, Ed., New York, Pergamon Press (1961).

6. Amiri, K., Soltani, M.R., Haghiri, A. and Mani, M. "An experimental investigation of effects of wall porosity and suction on the flow quality in a transonic wind tunnel", JAST, 6(2), pp. 63-70 (2009).

7. Grunnet, J.L. "Transonic wind tunnel wall interference minimization.", J. Aircraft, 21(9), pp. 694-699 (1984).

8. Medved, B.L. "An experimental investigation of the static pressure fluctuation mechanism for porous transonic wind tunnel wall configurations", Exp. Fluids, 15(6), pp. 401-410 (1993).

9. Glazkov, S.A., Gorbushin, A., Ivanov, A.I. and Semenov, A.V. "Recent experience in improving the accuracy of wall interference corrections in TsAGI T128 wind tunnel", Prog. Aerosp. Sci., 37(3), pp. 263298 (2001).

10. Rasuo, B. "Numerical and experimental analysis of transonic wind tunnel wall interference problem", In 13th Australian Fluid Mechanic Conference, Monash University, Melbourne, Australia (1998).

11. Doerffer, P.P. and Bohning, R. "Modelling of perforated plate aerodynamics performance", Aerosp. Sci. Trchnol., 8(4), pp. 525-534 (2000).

12. Hashimoto, A., Kohza, M., Aoyama, T. and Murayama, M. "Wall interference analysis of transonic wind tunnel with porous wall model", in 29th AIAA Applied Aerodynamics Conference, Honolulu, Hawaii (2011).

13. Davis, J.W. "Optimization of wave cancellation in variable porosity transonic wind tunnel flows", NASA, Alabama, TN D-7432 (1973).

14. Marino, A. and Bonfiglioli, A. "Optimization of the porosity distribution in transonic wind tunnel", In ASME, Rio Grande, pp. 35-45 (2012).

15. Rasuo, B. "On boundary layer control in twodimensional transonic wind tunnels", In Int. Conference on Boundary and Interior Layers, BAIL (2006).

16. Werling, M.G. "Static and dynamic calibration of a multi-component sidewall force balance for a transonic Ludwieg tube wind tunnel", University of Texas, Arlington, M.Sc. Thesis (2011).

17. Harris, C.D. "NASA supercritical airfoils", NASA Langley Research Center, Hampton, Technical Paper NASA TP-2969 (1990).

18. Blackwell Jr., J.A. and Pounds, G.A. "Wind-tunnel wall interference effects on a supercritical airfoil at transonic speeds", J. Aircraft, 14(10), pp. 929-935 (1977).

19. Tijdeman, H. "Investigations of the transonic flow around oscillating airfoil", Delft University of Technology, Delft, PhD Thesis, pp. 1181-1563 (1977).

20. Hess, R.W., Seidel, D.A., Igoe, W.B. and Lawing, P.L. "Transonic unsteady pressure measurements on a supercritical airfoil at high Reynolds numbers", $J$. Aircraft, 26(7), pp. 605-614 (1989). 
21. Hartmann, A., Klaas, M. and Schröder, W. "Experimental investigation of coupled heave/pitch oscillations in transonic flow", in 29th AIAA Applied Aerodynamics Conference, Honolulu, Hawaii (June 2011).

22. Piatak, D.J. and Cleckner, C.S. "Oscillating turntable for the measurement of unsteady aerodynamic phenomena", J. Aircraft, 40(1), pp. 181-188 (2003).

23. Hillenherms, C., Schröder, W. and Limberg, W. "Experimental investigation of a pitching airfoil in transonic flow", Aerosp. Sci. Technol., 8(7), pp. 583590 (2004).

24. Bland, S.R. and Edward, J.W. "Airfoil shape and thickness effects on transonic airloads and flutter", $J$. Aircraft, 21(3), pp. 209-217 (1984).

25. Golestani, A., Ehghaghi, M.B. and Soltani, M.R. "An experimental study of buffet detection on supercritical airfoils in transonic regime", P I Mech. Eng. G-J Aer., 229, pp. 312-322 (2014).

26. Dadone, L.U. "Two-dimensional wind tunnel test of an oscillating rotor airfoil", NASA, Philadelphia, Pennsylvania, Contractor Report 2914 (1977).

27. McDevitt, J.B. and Okuno, A.F. "Static and dynamic pressure measurements on a NACA 0012 airfoil in the Ames high Reynolds number facility", NASA, Moffett Field-California, Technical paper TP-2485 (1985).

28. The Expression of Uncertainty and Confidence in
Measurement, 3rd Ed., Middlesex, United Kingdom: UKAS Publication M 3003 (2012).

29. Launder, B.E. and Spalding, D.B. "The numerical computation of turbulent flows", Comput. Method Appl. M, 3, pp. 269-289 (1974).

\section{Biographies}

Ali Golestani is an Assistant Professor in the University of Tabriz. He received his $\mathrm{PhD}$ degree in Mechanical Engineering from University of Tabriz in 2014. His research interests are wind tunnel testing, CFD, Turbo machinery, and Combustion.

Mohammad Reza Soltani is a Professor at the Aerospace Engineering Department of Sharif University of Technology, Tehran, Iran. He has a PhD degree in aerodynamics from the University of Illinois at Urbana-Champaign, USA. His research interests include applied aerodynamics, unsteady aerodynamics wind tunnel testing, wind tunnel design, and data processing.

Mehran Masdari is an Assistant Professor at the New Sciences and Technologies Department in University of Tehran. He has a PhD degree in Aerospace Engineering from the Sharif University of Technology in 2011. His research interests are in applied aerodynamics, wind tunnel testing, neural network, and data processing. 